Article

\title{
Global Climate Responses to Land Use and Land Cover Changes Over the Past Two Millennia
}

\author{
Mi Yan ${ }^{1,2}$, Jian Liu ${ }^{1,2,3, *}$ and Zhiyuan Wang ${ }^{1}$ \\ 1 Key Laboratory of Virtual Geographic Environment of Ministry of Education \& State Key Laboratory \\ Cultivation Base of Geographic Environment Evolution of Jiangsu Province, School of Geography Science, \\ Nanjing Normal University, Nanjing 210023, China; myan@njnu.edu.cn (M.Y.); wzy_xiao@163.com (Z.W.) \\ 2 Jiangsu Center for Collaborative Innovation in Geographical Information Resource Development and \\ Application, Nanjing 210023, China \\ 3 Jiangsu Provincial Key Laboratory for Numerical Simulation of Large Scale Complex Systems, \\ School of Mathematical Science, Nanjing Normal University, Nanjing 210023, China \\ * Correspondence: jliu@njnu.edu.cn; Tel.: +86-186-6272-5225
}

Academic Editor: Robert W. Talbot

Received: 26 December 2016; Accepted: 18 March 2017; Published: 23 March 2017

\begin{abstract}
A reconstructed land use/land cover change (LUCC) dataset was used with the Community Earth System Model (CESM) to conduct a climate sensitivity analysis over the past two millennia. Compared to a controlled experiment conducted with the CESM, the LUCC showed significant biogeophysical effects on global climate on multi-decadal to centennial time scales. The global annual mean temperature and precipitation show clear decadal and multi-centennial scale oscillations when the LUCC effect was considered in the CESM simulation. With increased crop acreage and decreased natural vegetation over the past two millennia, the reflected terrestrial solar radiation has increased and the net terrestrial radiation has decreased, leading to a decrease in the global annual mean temperature. Global annual mean precipitation has also decreased along with decreased evaporation and atmospheric humidity. Our simulation suggests that LUCC mainly influences convective precipitation and has little influence on large-scale precipitation. The impact of LUCC has latitudinal and seasonal differences. The largest response of temperature to LUCC has occurred in the middle latitudes of the Northern Hemisphere $(\mathrm{NH})$, while the largest precipitation response occurred at lower latitudes of the NH. The responses of temperature and precipitation to LUCC is stronger in winter and spring than in summer and autumn.
\end{abstract}

Keywords: two millennia; historical LUCC; biogeophysical effect; global climate; climate simulation

\section{Introduction}

The impacts of land use/land cover change (LUCC) on climate change are components of global climate change research [1,2]. Tropical forests can reduce atmospheric $\mathrm{CO}_{2}$ concentrations [3], slow down global climate change [4], and reduce warming by evaporative cooling. The low albedo of northern forests can generate a positive radiative forcing, but the evaporative effects of temperate forests remains unclear [5]. Therefore, the net climate effects of these processes require further study.

Many studies have focused on the impact of LUCC on climate since the late 1970s [6-13]. These studies demonstrate that on a regional scale, the influence of LUCC on temperature can be comparable to that of increased $\mathrm{CO}_{2}$ [14]. The influence of LUCC on regional hydrometeorology is also equivalent to the influence of other climate factors (e.g., the El Niño-Southern Oscillation, ENSO) $[15,16]$. Studies of tropical forests such as the Amazon rainforest, show that deforestation can significantly influence local precipitation [17-19]. Li et al. [20] and Gao et al. [21] used numerical simulations of modern and contemporary land use changes in China to demonstrate that land use 
change had a large influence on precipitation in different areas. However, other studies reported that the influence of vegetation change on precipitation in China was not significant [22]. Although LUCC may significantly affect regional climate, the magnitude of its effects is controversial. Research results regarding LUCC effects on global climate are limited and debatable. Brovkin et al. [23] concluded that the influence of land cover change (predominantly deforestation) on the global climate was equivalent to the effects of factors such as greenhouse gases and solar radiation. However, Findell et al. [24] determined that the influence of anthropogenic land cover change (e.g., forest conversion to grassland) on the global climate change was trivial. Gibbard et al. [25] conducted a simulation study and concluded that actions such as the replacement of current vegetation by trees on a global basis may increase global temperature by up to $1.3{ }^{\circ} \mathrm{C}$. Arora and Mentenegro [26], in another simulation study, found that returning the area presently occupied by crops to forests could decrease global warming by $0.45^{\circ} \mathrm{C}$. Clearly, the impacts of LUCC on global and regional climate are largely uncertain and therefore warrant further study.

Most of the previous literature has involved various sensitivity experiments. For example, Zhang et al. [27] studied the impact of future grassland changes on surface climate in Mongolia. Brovkin et al. [28] evaluated the climate response to different greenhouse gas concentration scenarios with and without land-use changes. Notaro et al. [29] investigated the influence of fractional change in vegetation cover on the monsoon climate. However, studies on climate that consider the effects of transient LUCC are relatively rare, especially on centennial and millennial scales. Research on inter-annual LUCC needs to be more detailed [30], and more studies on the climate impacts of LUCC over longer time-scales are required. These studies may be significant in estimating climate change during the 21st century. Previous studies on the effects of LUCC have been limited to either modern times $[30,31]$ or the past 300 years [2,32]. The climatic effect of LUCC at decadal to centennial time-scales is rare and requires further study.

We have collected a LUCC dataset covering a time span of 2000 years from 1 to 2000 AD [33]. The last 2000 years has been a key research period of the Past Global Changes (PAGES) project [34], and climate simulation over 2000 years is an effective method for studying the climate effects of LUCC and quantitatively differentiating the impacts of natural factors and human activities on climate change. The features and mechanisms of long-term variability in global climate change and regional climate change have been reconstructed in References [35-37] and simulated in References [38-42]. However, the climate effects of LUCC on longer time-scales over the past 2000 years remain unclear. This paper used the reconstructed LUCC dataset in the Community Earth System Model (CESM) to conduct LUCC single-factor climatic sensitivity experiments over the past two millennia. By comparing the results to a control experiment with fixed land cover, we analyzed the global climate effects of historical LUCC, with an emphasis on the global climate effects of LUCC on multi-decadal to centennial time-scales.

\section{Model and Data}

\subsection{Model and Experiment}

We conducted climate simulation experiments using Community Earth System Model (CESM) developed by the US National Center for Atmospheric Research (NCAR) [43]. Compared to the simple coupling model utilized in previous research, the CESM model integrates the physical and chemical processes of various sub-systems relating to the land, ocean, atmosphere, sea ice, and land ice [39], which provides better conditions for studying the climate effects of LUCC. Furthermore, the land model used in this study is the Community Land Model Version 4.0 (CLM4) and includes transient LUCC and developed parameters, which can study the role of land processes in climate change [44,45].

We performed two climate simulation experiments, where each was integrated for more than 2000 years. One experiment was control run using fixed external forcing conditions of 1850 (CTRL run), and the other was a single-factor climatic sensitivity experiment using transient land use and cover change (LU run). The CTRL run started from model year 1, the ocean state in $2010 \mathrm{AD}$ (provided 
by NCAR) was used as the initial condition, and the experiment was integrated 2400 years [46]. The energy balance at the top of atmosphere (TOA) showed that the coupled climate system reached its balance after 400 years' spin-up (Figure S1). The LU run, initiated from the last year of the control run, was integrated over 2000 years with the reconstructed yearly LUCC data during the period from 1 to $2000 \mathrm{AD}$ with a dynamic vegetation process. The first 200-year simulations of the LU run were discarded for spin-up, with only the last 1800-year simulations used for analysis. To facilitate comparison, the CTRL run used results for the last 1800 years. The T31 atmosphere model selected had a horizontal resolution of approximately $3.75^{\circ}$ (latitude) $\times 3.75^{\circ}$ (longitude), and the ocean model had a resolution of about $1.5^{\circ}$ (latitude) $\times 3.6^{\circ}$ (longitude). Our climate change focus was on a 10-100-year time scale, and unless noted, a 31-year moving-average process was used for the time series.

The carbon-nitrogen $(\mathrm{CN})$ biogeochemical model was not considered in our experimental design and focused only on the biogeophysical impacts of the LUCC on global climate. Furthermore, although the CTRL and LU experiments did not represent actual climate states, the results from the LU experiment could reveal a climate response to the LUCC. Finally, we only considered how global climate would be affected by the reconstructed LUCC over the past two millennia.

\subsection{LUCC Data}

The external forcing data used to conduct the LUCC single-factor sensitivity experiment was from the reconstructed results (KK10) provided by Kaplan et al. [47]. Yan et al. [33] had also previously collected and compared several LUCC reconstructed datasets with scales $>1000$ years, and adopted the KK10 dataset. This dataset was reconstructed using a deforestation model based on the relationship between population and land use, and covers the variation, in fractions, of 14 vegetation types over the past 2000 years (1-2000 AD). The temporal resolution was one year, and the spatial resolution was $0.5^{\circ} \times 0.5^{\circ}$. The fraction of a specific vegetation type refers to the percentage of that specific vegetation in the unit grid. For example, if $50 \%$ of the unit grid are crops, then the crop ratio was specified as $50 \%$. The land surface model of CESM divides the vegetation into 16 different types [48] (Table 1), so the reconstructed data was re-categorized and processed. A one-to-one mapping method was primarily used to rearrange the KK10 data or split the original data as per the ratio of 50\% (Kaplan and Chen, pers. comm.) (Table S1), and this approach provided vegetation type data suitable for the CESM land component.

It was noted that the Evergreen shrubs, C3 pasture and C4 pasture in the KK10 had no comparative types in CLM4, thus, the anthropogenic land cover change in CLM4 was only represented by the change of the Crop 1 fraction.

Table 1. Vegetation types in Kaplan data and the Community Earth System Model (CESM) required data.

\begin{tabular}{ccc}
\hline No. & Vegetation Type (Kaplan) & Vegetation Type (CESM) \\
\hline 1 & Tropical evergreen forest & Temperate evergreen forest \\
2 & Tropical deciduous forest & Boreal evergreen coniferous forest \\
3 & Temperate evergreen broad-leaved forest & Boreal deciduous coniferous forest \\
4 & Temperate/boreal evergreen broad-leaved forest & Tropical evergreen broad-leaved forest \\
5 & Temperate/boreal evergreen needle-leaved forest & Temperate evergreen broad-leaved forest \\
6 & Temperate/boreal deciduous coniferous forest & Tropical deciduous broad-leaved forest \\
7 & Evergreen shrubs & Temperate deciduous broad-leaved forest \\
8 & Deciduous shrubs & Boreal deciduous broad-leaved forest \\
9 & C3 natural grassland & Temperate evergreen broad-leaved shrubs \\
10 & C4 natural grassland & Temperate deciduous broad-leaved shrubs \\
11 & Tundra & Boreal deciduous broad-leaved shrubs \\
12 & Crop & C3 polar grass (tundra) \\
13 & C3 pasture & C3 grassland \\
14 & C4 pasture & C4 grassland \\
15 & & Crop 1 1 \\
16 & The surface data applied in the model only used the first type of crop.
\end{tabular}


The change of the fractions of 16 vegetation types (including crops, grassland, and other natural vegetation types) used in the LU sensitivity experiments in the past two millennia are shown in Figure 1. In the past two millennia, the ratio of the crops, reflecting the impacts of human activities, have increased (dashed line in Figure 1). After the industrial revolution, the fractions of crops rapidly increased, reaching $15.5 \%$ in 2000 . The fractions of natural vegetation decreased during this period (solid line in Figure 1), except for a slight increase in the C3 and C4 grassland fractions.

Compared to the fixed data of $1850 \mathrm{AD}$ used in the control run, regional differences existed in LU during the past two millennia. In most world regions, the ratios of multi-year average crops in the LU run were higher than in the control run, which was related to the massive deforestation caused by human activities. However, the ratios of crops in the middle regions of the US and partial regions in mid-Asia decreased slightly and the ratio of natural vegetation increased, which may be due to reforestation and afforestation. Therefore, compared to the average conditions in 1850 used by the control run, the ratio of forest cover used in the LU sensitivity experiment increased in central North America, Central Eurasia, and Equatorial Asia. However, the ratio of crops in most world regions remained higher than the value produced in the control run (Figure 2 and Figure S2).

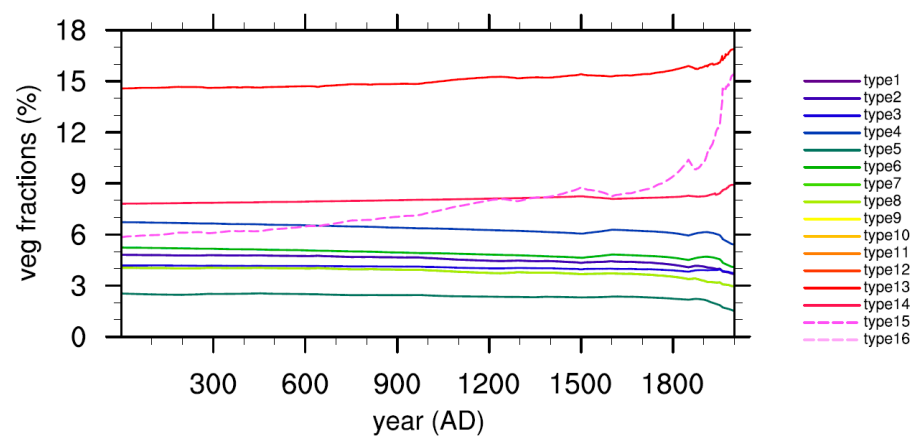

Figure 1. Time series of the fraction changes of 16 vegetation types used in LU sensitivity experiments over the past 2000 years. Dashed lines indicate the time series of the fraction changes of Crop 1 (type 15) and Crop 2 (type 16), and the solid lines are the time series of fraction changes of various natural vegetation.
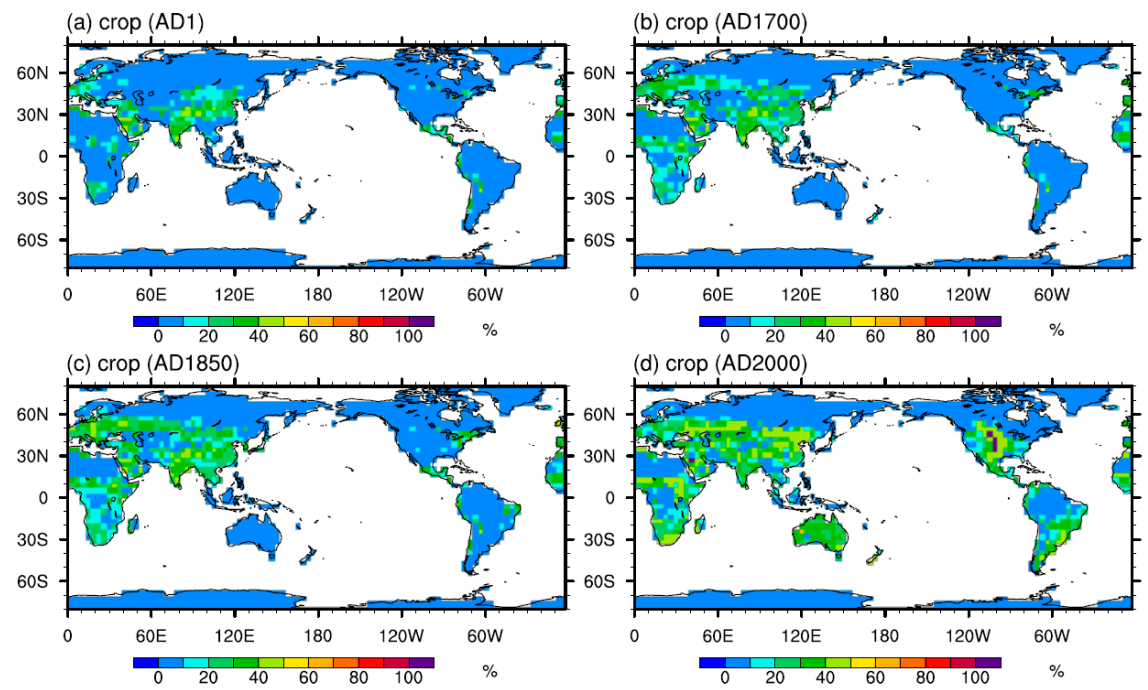

Figure 2. Spatial distributions of anthropogenic vegetation fractions (crops) during four periods. (a-d) represent 1 AD, 1700 AD, $1850 \mathrm{AD}$ and 2000 AD, respectively, used in the LU run. 


\section{Results}

\subsection{Global Climate Effects}

\subsubsection{Temperature Response}

The global mean surface temperature (including land- and sea surface temperatures) showed a decreasing trend in the LU experiment over the past 1800 years (Figure 3a). This was particularly obvious prior to $700 \mathrm{AD}$, where the surface temperature remained at a relatively high level. During this period, LUCC, especially the change in the ratio of crops reflecting human activities, was relatively small; however, between 700 and 1100 AD, cooling-warming-cooling fluctuations with relatively large amplitudes occurred, and from 1200 to 1800 AD, the temperature changed little (blue line in Figure 3a). After $1800 \mathrm{AD}$, the ratio of crops rapidly increased and the ratio of the natural vegetation decreased. During this period, temperature decreased and global surface temperature reached the lowest level of past 1800 years. LUCC caused a decrease in annual- and global-mean temperature by $0.004{ }^{\circ} \mathrm{C}$ per hundred years $(p<0.05)$.

Figure $3 b, c$ illustrates the results of a power spectrum analysis of the global annual mean surface temperature (without the 31-year moving average). As the annual periodicity of both surface temperatures in the control run and the LU sensitivity experiment was significant, to highlight decadal periodicity, Figure 3b,c shows periods longer than 20 years. From these two figures, the approximate 200 -year period was significant above the 95\% confidence level $(p<0.05)$ in the control run, while the approximate 200-year period in the LU sensitivity experiment was not significant. In contrast, in the LU sensitivity experiment, the approximate 50-year, 100-year, 300-year and 400-year periods all exceeded the $95 \%$ confidence level $(p<0.05)$.

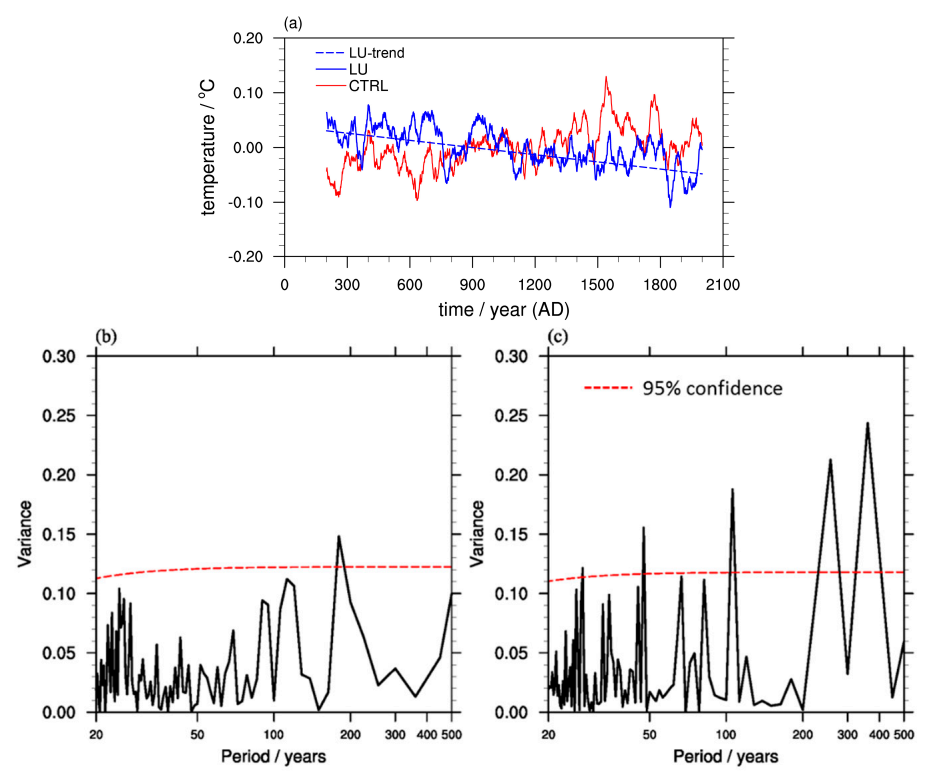

Figure 3. (a) Time series of the global annual mean surface temperature anomalies in the past 1800 years (compared to the 201-2000 AD). After the 31-year running mean process, the red line indicates the result of the control run, the blue curve is the result of single-factor sensitivity experiment, and the blue dashed line is the variation trend of the surface temperature in the single-factor sensitivity experiment; $(\mathbf{b}, \mathbf{c})$ Power spectrum of global annual average surface temperature, which here only displays periodic variation conditions over 20 years; where (b) shows the results of the control run; and (c) the results of the LU sensitivity experiment. The red dashed line indicates the $95 \%$ confidence level.

In the LU experiment, the decreasing trend of global temperatures in winter and spring was more apparent than that summer and autumn. The decreasing trend of the temperatures in winter and 
spring were $0.0053^{\circ} \mathrm{C}$ per 100 years and $0.005^{\circ} \mathrm{C}$ per 100 years, respectively, and the decreasing rates in summer and autumn were $0.0034^{\circ} \mathrm{C}$ per 100 years and $0.0038^{\circ} \mathrm{C}$ per 100 years.

Regions with a relatively large increase in crops were mainly located at the mid-latitudes in the Northern Hemisphere $(\mathrm{NH})\left(30-50^{\circ} \mathrm{N}\right)$ and the temperature responses at different latitudes were shown in Figure $4 a, b$ and the spatial distribution of the temperature change in Figure S3. Though the amplitude of the temperature change in the high-latitude $\mathrm{NH}\left(60-90^{\circ} \mathrm{N}\right)$ was the greatest, the trend was not. The maximum temperature reduction was seen in the mid-latitude $\mathrm{NH}\left(30-60^{\circ} \mathrm{N}\right)$ ( $0.01{ }^{\circ} \mathrm{C}$ per 100 years), which corresponded to the latitude zone showing a maximum increase in crops and pastures. The temperature reduction trends in the low-latitude $\mathrm{NH}\left(0-30^{\circ} \mathrm{N}\right)$ and the Southern Hemisphere $(\mathrm{SH})\left(0-90^{\circ} \mathrm{S}\right)$ were relatively small. Furthermore, the spatial distribution of the annual mean temperature trend also illustrated that the temperature decreased more over the $\mathrm{NH}$ mid-latitudes, particularly over the Eurasian continent, under the LUCC forcing (Figure 4c).
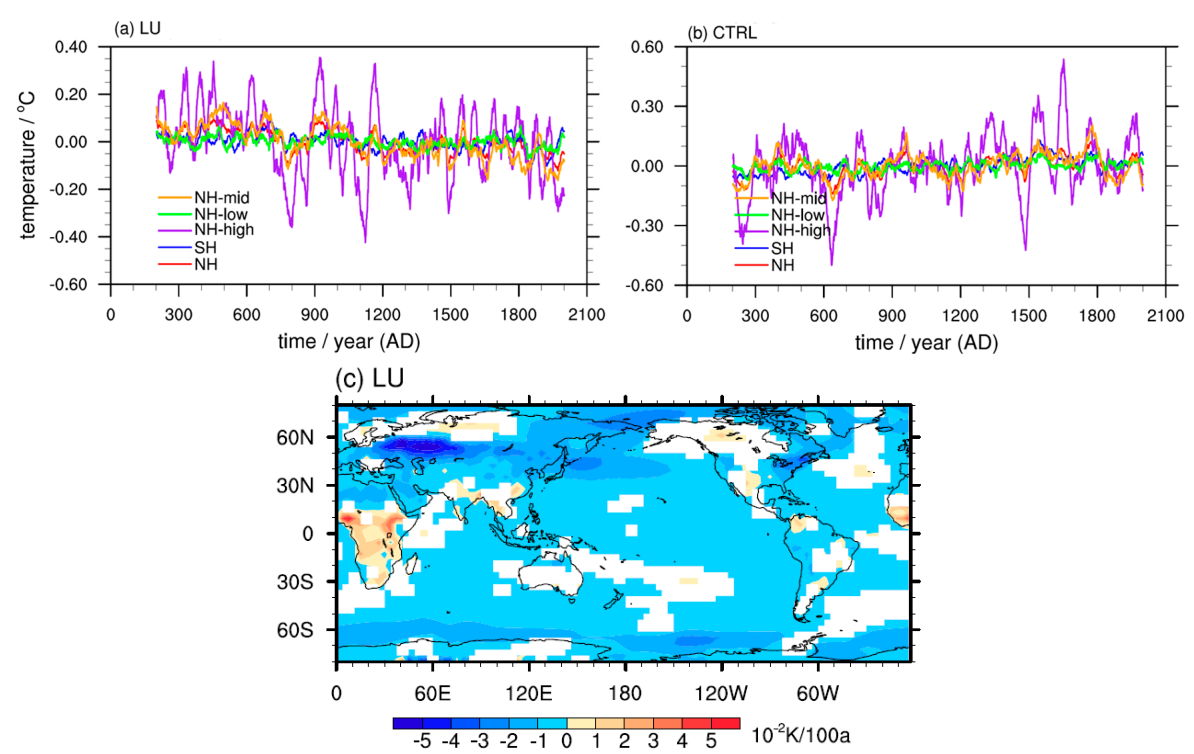

Figure 4. Time series of annual average surface temperature anomalies over different latitudes in the past 1800 years. (a) LU run; (b) control (CTRL) run; and (c) the spatial distribution of temperature trend derived from the LU run, only areas that exceeded the $99 \%$ confidence level are plotted.

In addition to the impacts of LUCC on the long-term trend of temperature, LUCC also leads to multi-decadal or even multi-centennial variation periods of temperature. In different seasons, the impact of LUCC occurred primarily in the first half of the year (winter and spring), and was relatively larger compared to the second half of the year (summer and autumn). The temperature response to LUCC in the mid-latitude $\mathrm{NH}$ was the strongest.

\subsubsection{Precipitation Response}

In the LU experiment, the global annual mean precipitation showed a decreasing trend associated with multi-decadal to centennial variabilities over the past 1800 years (indicated by the blue line in Figure 5a). The reduced rate of precipitation was $0.1 \mathrm{~mm}$ per 100 years, and global precipitation reached its lowest level at $1800 \mathrm{AD}$. In relation to global surface temperature, precipitation changed $0.06 \mathrm{~mm} /$ day per degree of the temperature change.

The power spectrum analysis of global annual mean precipitation (Figure $5 b, c$, without the 31-year moving average) indicated that global precipitation in the control run and the LU experiment both showed inter-annual variabilities. There were no significant periodicities longer than the inter-annual time-scale in the control run; however, in the LU sensitivity experiment, significant 50-year, 100-year, and 400-year periods occurred. 
The global annual mean temperature and precipitation were reduced to $0.05 \mathrm{~K}$ and $0.01 \mathrm{~mm} /$ day, respectively, when compared to the results derived from the LU run to the CTRL run. The precipitation changed $7.5 \%$ per degree of temperature change, which exceeded the thermodynamic effect governed by the Clausius-Clapeyron equation ( $7 \%$ moisture change per degree of temperature change). We assumed that the LUCC would affect global climate primarily through the thermodynamic effect. Along with increased crops and a decrease in natural vegetation, the differences between the LU and CTRL run became larger and more significant on a centennial time scale (Table S2).
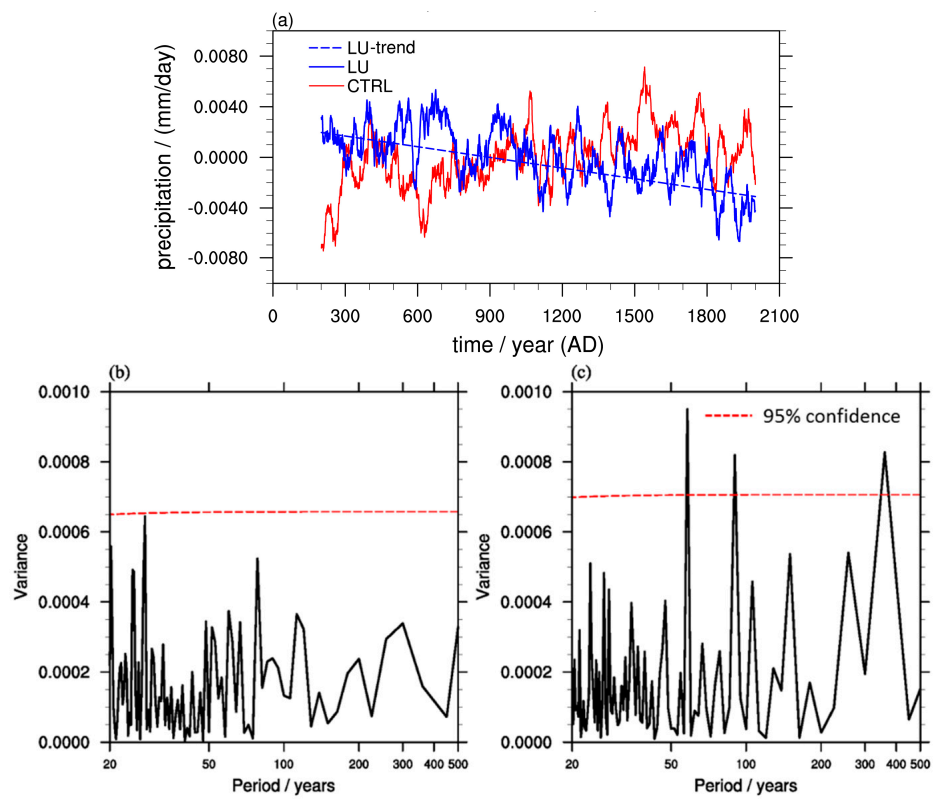

Figure 5. (a) Time series of the global annual mean precipitation rate anomalies in the past 1800 years (compared to the 201-2000 AD). After the 31-year running mean process, the red line is the result of the control run, the blue curve is the result of the single-factor sensitivity experiment, and the blue dashed line is the variation trend of the surface temperature in the single-factor sensitivity experiment; $(\mathbf{b}, \mathbf{c})$ Power spectrum of global annual average precipitation rate, which only displays the periodic variation conditions over 20 years; where (b) are the results of the control run; and (c) are the results of the LU sensitivity experiment. The red dashed line is the $95 \%$ confidence level.

Figure $6 \mathrm{a}, \mathrm{b}$ show the 1800 -year time series of annual precipitation at different latitudes under the effect of LUCC and in the CTRL run. Precipitation showed a stronger variability in the low latitudes relative to the middle and high latitudes, and its long-term trend was also relatively large at $0.146 \mathrm{~mm}$ per 100 years. The trend of precipitation decline in the mid-latitude $\mathrm{NH}$ was also relatively large at $0.153 \mathrm{~mm} / 100$ years. The spatial distribution of the annual mean precipitation change also showed that the precipitation changes were larger over the low latitudes of NH (Figure S4). The long-term trends of precipitation in the $\mathrm{NH}$ and the SH were relatively small, with values of $0.084 \mathrm{~mm}$ per 100 years and $0.066 \mathrm{~mm}$ per 100 years, respectively. However, in the LU experiment, the variation amplitude and rates of convective precipitation were both greater than those of large-scale precipitation (Figure 6c). For precipitation during different seasons, the impacts of LUCC on precipitation in winter $(0.128 \mathrm{~mm}$ per 100 years) and spring $(0.107 \mathrm{~mm}$ per 100 years) were slightly greater than the impacts in summer (0.086 mm per 100 years) and autumn (0.091 mm per 100 years). 


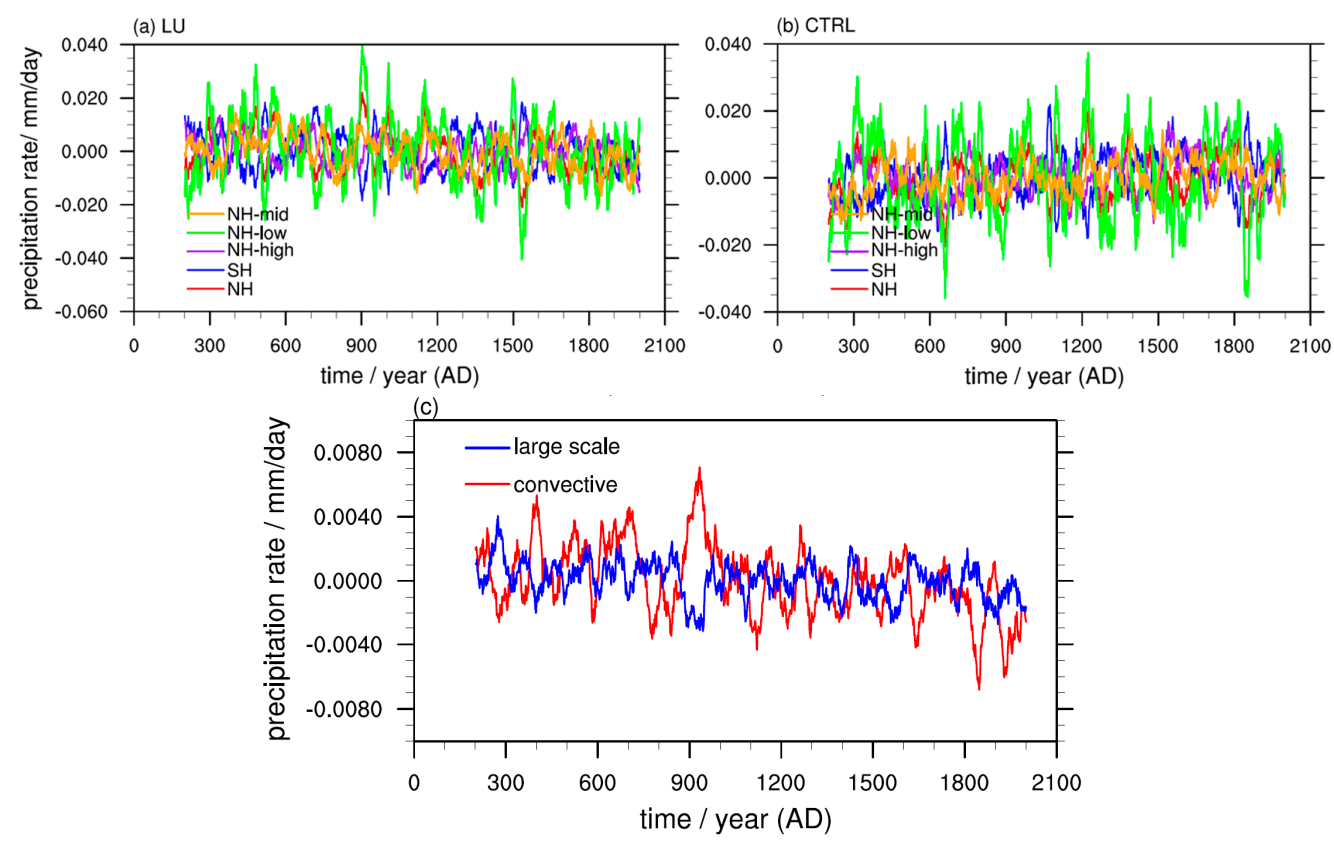

Figure 6. Time series of annual average precipitation rate anomalies over different latitudes in the past 1800 years. (a) LU run; (b) for CTRL run; and (c) the time series of global annual mean convective precipitation rate anomaly (red line) and large-scale precipitation rate anomaly (blue line).

\subsection{Analysis of Mechanisms}

\subsubsection{Mechanisms of Temperature Variation}

On a multi-decadal to centennial time scale over the last 1800 years, crops increased and natural vegetation decreased, especially due to a reduction of $\mathrm{NH}$ forests. While this occurred, the solar radiation reflected by the ground surface increased at a rate of $0.02 \mathrm{~W} / \mathrm{m}^{2}$ per 100 years (Figure 7). The net surface radiation had a decreasing trend of $0.03 \mathrm{~W} / \mathrm{m}^{2}$ per 100 years. Under the effect of LUCC, the average global ground surface reflection radiation increased by $0.22 \mathrm{~W} / \mathrm{m}^{2}$, surface ground net radiation was reduced by $0.22 \mathrm{~W} / \mathrm{m}^{2}$, and surface heat flux was reduced by $0.08 \mathrm{~W} / \mathrm{m}^{2}$. Furthermore, the surface latent flux was reduced by $0.18 \mathrm{~W} / \mathrm{m}^{2}$, and the surface sensible flux increased by $0.1 \mathrm{~W} / \mathrm{m}^{2}$, where global temperature consequently showed a decreasing trend. LUCC caused a decrease in the surface net radiation by $1 \mathrm{~W} / \mathrm{m}^{2}$ as well as a decrease in temperature by $0.15^{\circ} \mathrm{C}$.

Among the different latitudes, the regions showing the strongest ground surface reflection of solar radiation were in the mid-latitude $\mathrm{NH}$ (Figure 8), which were the regions showing the greatest cropland expansion. Thus, the influence of LUCC on temperature was relatively direct, and was realized via a thermodynamic mechanism. A previous study in Reference [49] suggested that converting crops in the mid-latitude $\mathrm{NH}$ to deciduous coniferous forest led to an increase in the absorbed solar radiation and the sensible heat flux, which in turn resulted in temperature increases in these areas. These results were consistent with the conclusions of this paper. 


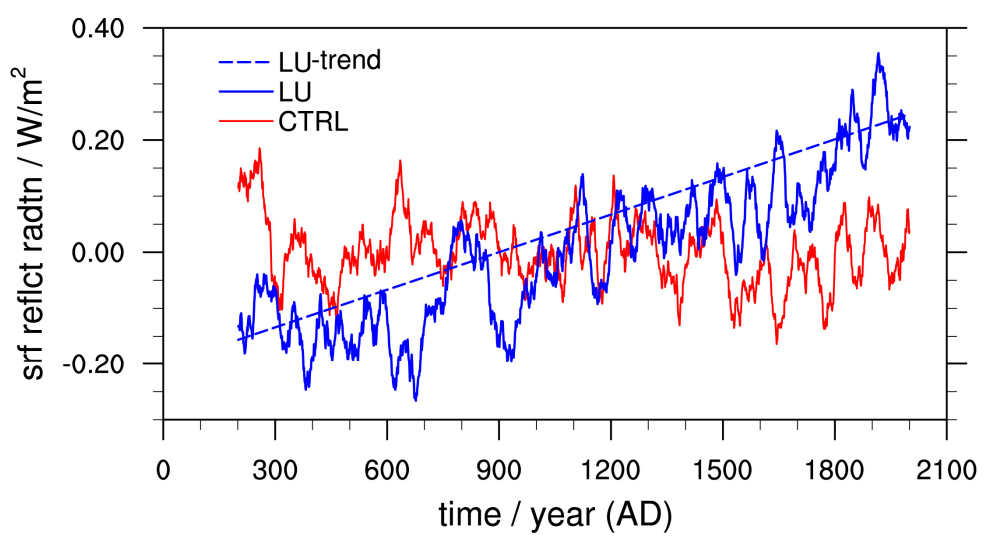

Figure 7. Time series of annual mean surface reflected solar radiation anomalies. The description of the lines is the same as that provided in Figure 2a.

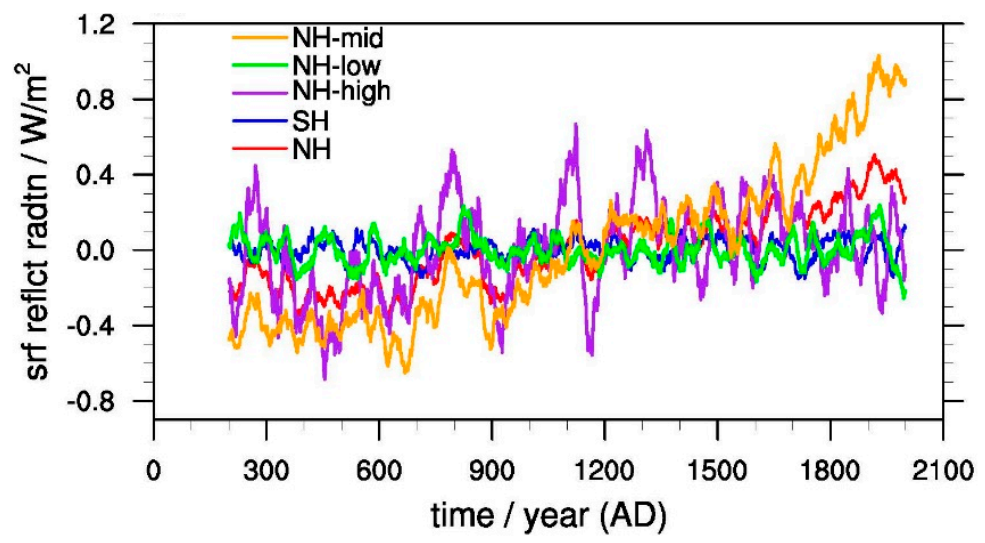

Figure 8. Time series of the annual mean surface reflected solar radiation anomalies over different latitudes (the difference between the results derived from the LU sensitive run and the control run).

In winter and spring, the albedo of the crops covered by snow was greater than the albedo of the forest covered by snow [50,51]. Summer and autumn tend to be when crops grow vigorously, and the albedo of the vegetation was reduced compared to those of winter and spring. The difference in the albedo of different types of vegetation varied from one season to another, which was one of the reasons why different vegetation types can have a large influence on the temperatures in spring and winter. Hua and Chen [30] also demonstrated that on an inter-annual scale, the influence of LUCC on temperatures in the mid-latitude regions can be more significant in winter and spring than in summer and autumn.

To further investigate the multi-decadal periodicity of temperature, we applied a 30-50 year band-pass filter and then applied an Empirical Orthogonal Function (EOF) analysis to the surface temperature (including sea surface temperature). We found an Atlantic multi-decadal oscillation (AMO) pattern and a Pacific decadal oscillation (PDO) pattern in the LU run, which was absent in the CTRL run (Figure S5). Therefore, we considered that the enhanced multi-decadal variation may be related to both the PDO and AMO.

\subsubsection{Mechanism of Precipitation Variation}

As the ratio of the global crops increased and the ratio of natural vegetation decreased, surface evaporation in the past 1800 years shows a decreasing trend (Figure 9a). Correspondingly, the concentration of water vapor in the atmosphere has declined, and atmospheric humidity also shows a clear decreasing trend (Figure 9b), especially after 1850 AD when surface evaporation and 
the large reduction in atmospheric humidity resulted in a reduction in global precipitation. The dramatic decreasing trend of surface evaporation during the last 100 years was likely the result of LUCC, especially after $1850 \mathrm{AD}$ when the temperate forests were largely replaced by cropland (Figure 2 and Figure S1). With increased crops and decreased natural vegetation, the reflected terrestrial solar radiation increased and the net terrestrial radiation decreased, leading to a decreasing trend in evaporation during that period. In addition, the decreased surface temperature may have decreased evaporation, especially over the ocean, which may have contributed to a decrease in precipitation. Thus, LUCC leads to a decreased trend in the surface sensible heat flux in the past 1800 years, which corresponded to a weakening of the upwelling and atmosphere convection convergence [52], which hampered the formation of precipitation, especially convective precipitation.
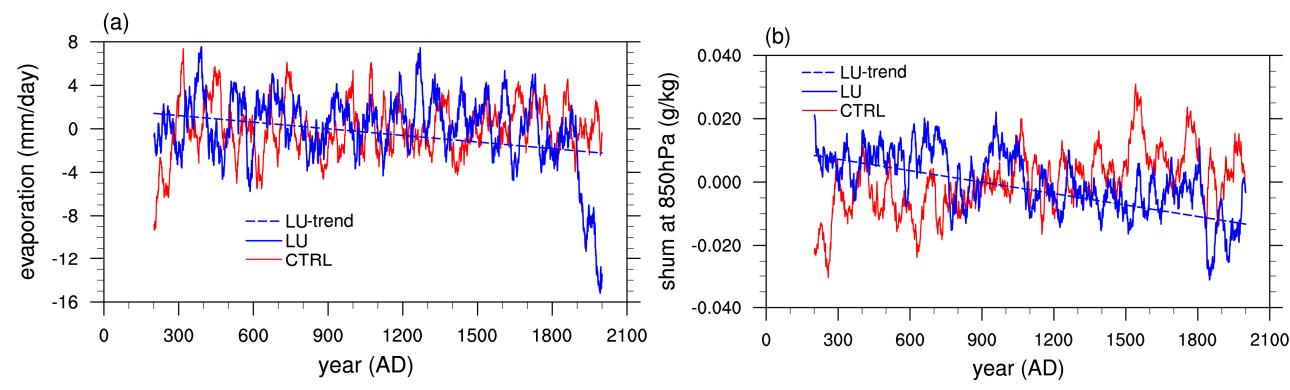

Figure 9. (a) Time series of annual mean evaporation anomalies; and (b) specific humidity anomalies at $850 \mathrm{hPa}$. The demonstration of the lines is the same as in Figure 2a.

Figure 10 shows that the zonal wind field at $500 \mathrm{hPa}$ in the mid-latitude $\mathrm{NH}$ has increased since 1850. With increased crops in the mid-latitude regions, the middle latitude westerlies showed an increasing trend, and winds in winter and spring were relatively stronger. When the middle latitude westerlies were stronger in East Asia during winter, cold weather events frequently occurred, which may have led to reductions in the surface temperature and precipitation in East Asia [53]. We calculated the correlation coefficient between the annual mean zonal wind at $500 \mathrm{hPa}$ and temperature (precipitation). The results demonstrated that they were significantly related to each other under LUCC forcing. The correlation coefficient was $-0.45(-0.23)$ in the LU run, and it appears that the LUCC mainly affects the middle latitude westerly winds, thereby influencing precipitation in the mid-latitude regions.

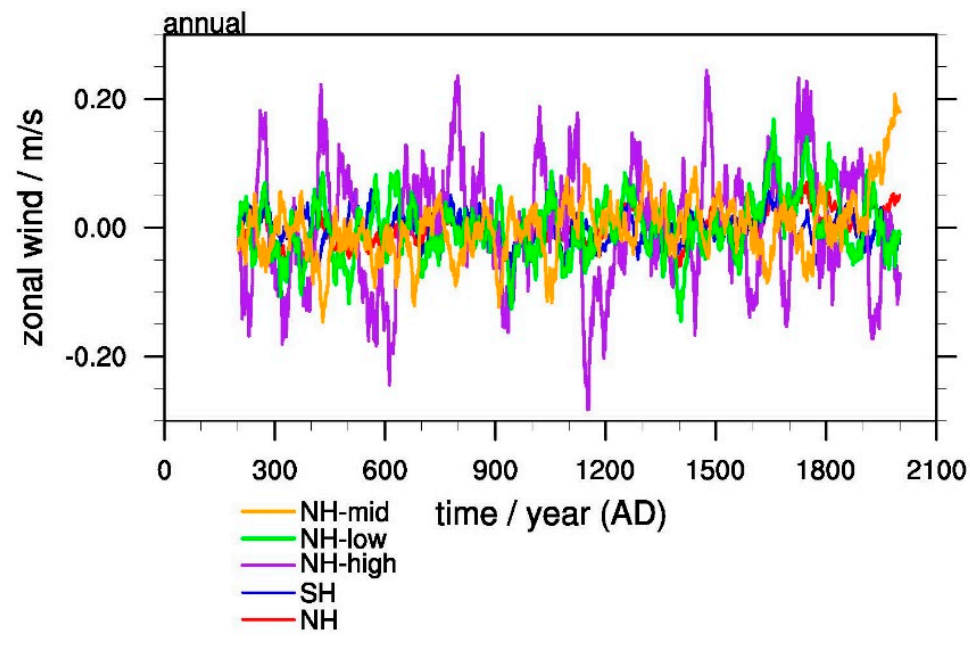

Figure 10. The annual mean zonal wind anomalies at $500 \mathrm{hPa}$ at different latitudes (the difference between the results derived from the LU sensitive run and the control run). 
At NH low latitudes, precipitation change may also be related to the changed Walker and Hadley circulations. For example, the temperature decreased and the ascending flow weakened over the Western Pacific warm pool and the descending flow also weakened over the Eastern Pacific Ocean, leading to a weakened Walker circulation over the entire Pacific Ocean. The weakened Walker circulation along with decreased specific humidity led to the decreased precipitation.

\section{Discussion}

Between $1200 \mathrm{AD}$ and $1700 \mathrm{AD}$, variables such as surface radiation, temperature and precipitation showed low variation, and the variations in the crop ratio was relatively small. After the industrial revolution, the crop ratio showed considerable variation, resulting in dramatic changes in factors such as net surface radiation, surface temperature, evaporation, and precipitation. Before $700 \mathrm{AD}$, the ratio and the variation in the crop ratio were both relatively small, and the change in each corresponding climatic factor was also relatively small. However, between $700 \mathrm{AD}$ and $1200 \mathrm{AD}$, there was a greater variation amplitude of the ratio of crops, resulting in dramatic changes in each climatic factor during this period. On a multi-decadal scale, LUCC has had a significant effect on the variation amplitude of the global climate, which is consistent with the conclusion that the LUCC effect would increase global temperature. This was also consistent with the occurrence of an approximate 400-year multi-decadal variation period in precipitation.

Prior to $700 \mathrm{AD}$, human population was low, and technology and the use of natural vegetation was minor. The variation amplitude of the crop ratio was low, and its climatic influence was also relatively small. The interval between $700 \mathrm{AD}$ and $1200 \mathrm{AD}$, represented a Medieval Warm Period where the climate was benign, population growth was rapid, crop cultivation increased as did the use of natural vegetation and resulted in a rapid increase in the crop ratio. Therefore, the global climate showed a relatively large variation. Between $1200 \mathrm{AD}$ and $1700 \mathrm{AD}$, the world entered the Little Ice Age, when population growth slowed, and the ratio of crops varied only slightly within a narrow range. As a result, climate change variation during this period was relatively moderate. Between $1700 \mathrm{AD}$ and $2000 \mathrm{AD}$, the climate once again entered a warming period, the human population rapidly increased, as did development and land utilization. The crop ratio increased rapidly, resulting in another period of climate change amplitude increase. The LUCC shows an interactive influence on climate, where climate change will influence human activities, thus influencing LUCC. LUCC also has a relatively large influence on the variation amplitude of the climate. During the 20th century, in contrast to the well-recognized global warming trend, LUCC appears to be associated with a decreasing trend in global temperature.

By comparing the time series of the ratio of global crops in the past 1800 years, as well as the time series of global temperature and precipitation, it is clear that in the relatively stable stages of global temperature and precipitation variation (e.g., 200-700 AD, and 1200-1700 AD), the crop ratio changed less than $1 \%$. During periods showing relatively larger variation in the amplitude of the global temperature and precipitation (e.g., 700-1200 AD, and post $1700 \mathrm{AD}$ ), the variation in the ratio of crops exceeded $1 \%$. It is unclear at this stage whether a threshold must be reached before the LUCC shows significant influence on the global climate, which will require additional research.

\section{Conclusions}

A comparison of the LU sensitive run to the CTRL run showed that the LUCC had a significant biogeophysical impact on global climate. In the past 1800 years, as croplands increased and natural vegetation decreased, global solar radiation reflected by the ground surface on multi-decadal and centennial scales showed an increasing trend. Additionally, decreased surface net radiation and a reduction in surface heat flux resulted in reduced global temperatures. The precipitation also showed a significant decreasing trend related to the changes of temperature, evaporation and wind field etc. Both the global annual mean temperature and precipitation showed significant oscillations at multi-decadal and centennial time-scales. 
The conclusions in this study are resulted from a single model and a single experiment. Whether the results are robust and model dependent will require further study. Additionally, the reconstructed LUCC datasets also contained large uncertainties [32], which may also have influenced the simulated results based on these datasets.

Supplementary Materials: The following is available online at www.mdpi.com/2073-4433/8/4/64/s1. Figure S1: Time series of energy balance at top of atmosphere (TOA) $(\mathrm{W} / \mathrm{m} 2)$ from CTRL run. The blue line represents annual mean TOA; the red line represents its linear trend in the last 2000 years. Figure S2; Spatial distributions of natural vegetation types during four periods, where (a-d) represent $1 \mathrm{AD}, 1700 \mathrm{AD}, 1850 \mathrm{AD}$ and $2000 \mathrm{AD}$, respectively, used in LU run. Figure S3: Spatial distributions of the annual mean surface temperature derived from (a) the CTRL run; and (b) the difference between the LU run and CTRL run. Only the areas exceeding the $95 \%$ confidence level are shown in (b). Figure S4: Spatial distributions of the annual mean precipitation rate derived from (a) the CTRL run; and (b) the difference between the LU run and CTRL run. Only those areas exceeding the $95 \%$ confidence level are shown in (b): Figure S5. Spatial pattern of the leading two EOF modes of annual surface temperature, after a 30-50 year band-pass filter. Left panel is derived from the LU run, right panel from the CTRL run. Table S1: IDs of vegetation type in the CESM land component and in Kaplan's classification. Table S2: Climatology of temperature and precipitation derived from the CTRL and LU runs and the difference for every 100 years during the last 1800 years.

Acknowledgments: We thank several reviewers for their constructive comments that assisted in clarifying and improving this paper. This work was jointly supported by the National Key Research and Development Program of China (Grant No. 2016YFA0600401), the National Natural Science Foundation of China (Grant Nos. 41302137, 41671197, 41371209 and 41420104002), and A Project Funded by the Priority Academic Program Development of Jiangsu Higher Education Institutions (PAPD, Grant No. 164320H116).

Author Contributions: M.Y. and J.L. designed the work. Z.W. ran the simulations. M.Y. performed analysis and wrote the initial manuscript. J.L. and M.Y. contributed to manuscript improvement and revisions.

Conflicts of Interest: The authors declare no conflicts of interest.

\section{References}

1. Liu, J.Y.; Shao, Q.Q.; Yan, X.D.; Fan, J.W.; Deng, X.; Zhan, J.Y.; Gao, X.J.; Huang, L.; XU, X.; Hu, Y.; et al. An overview of the progress and research framework on the effects of land use change upon global climate. Adv. Earth Sci. 2011, 26, 1015-1022.

2. Shi, Z.; Yan, X.; Yin, C.; Wang, Z. Effects of historical land cover changes on climate. Chin. Sci. Bull. 2007, 52, 2575-2583. [CrossRef]

3. Houghton, R.A.; Byers, B.; Nassikas, A.A. A role for tropical forests in stabilizing atmospheric $\mathrm{CO}_{2}$. Nat. Clim. Chang. 2015, 5, 1022-1023. [CrossRef]

4. Murdiyarso, D.; Purbopuspito, J.; Kauffman, J.B.; Warren, M.W.; Sasmito, S.D.; Donato, D.C.; Manuri, S.; Krisnawati, H.; Taberima, S.; Kurnianto, S. The potential of indonesian mangrove forests for global climate change mitigation. Nat. Clim. Chang. 2015, 5, 1089-1092. [CrossRef]

5. Bonan, G.B. Forests and climate change: Forcings, feedbacks, and the climate benefits of forests. Science 2008, 320, 1444-1449. [CrossRef] [PubMed]

6. Charney, J.; Stone, P.H.; Quirk, W.J. Drought in the sahara: A biogeophysical feedback mechanism. Science 1975, 187, 434-435. [CrossRef] [PubMed]

7. Sagan, C.; Toon, O.B.; Pollack, J.B. Anthropogenic albedo changes and the earth's climate. Science 1979, 206, 1363-1368. [CrossRef] [PubMed]

8. Shukla, J.; Mintz, Y. Influence of land-surface evapotranspiration on the earth's climate. Science 1982, 215, 1498-1501. [CrossRef] [PubMed]

9. Garratt, J.R. Sensitivity of climate simulations to land-surface and atmospheric boundary layer treatments-A review. J. Clim. 1993, 6, 419-449.

10. Bonan, G.B. Observational evidence for reduction of daily maximum temperature by croplands in the midwest United States. J. Clim. 1999, 9, 1305-1315. [CrossRef]

11. Foley, J.A.; DeFries, R.; Asner, G.P.; Barford, C.; Bonan, G.; Carpenter, S.R.; Chapin, F.S.; Coe, M.T.; Daily, G.C.; Gibbs, H.K.; et al. Global consequences of land use. Science 2005, 309, 570-574. [CrossRef] [PubMed]

12. Betts, R.A.; Golding, N.; Gonzalez, P.; Gornall, J.; Kahana, R.; Kay, G.; Mitchell, L.; Wiltshire, A. Climate and land use change impacts on global terrestrial ecosystems and river flows in the HADGEM2-ES earth system model using the representative concentration pathways. Biogeosciences 2015, 12, 1317-1338. [CrossRef] 
13. Xu, Z.; Mahmood, R.; Yang, Z.-L.; Fu, C.; Su, H. Investigating diurnal and seasonal climatic response to land use and land cover change over monsoon asia with the community earth system model. J. Geophys. Res. Atmos. 2015, 120, 1137-1152. [CrossRef]

14. Pitman, A.J.; Zhao, M. The relative impact of observed change in land cover and carbon dioxide as simulated by a climate model. Geophys. Res. Lett. 2000, 27, 1267-1270. [CrossRef]

15. Findell, K.L.; Pitman, A.J.; England, M.H.; Pegion, P.J. Regional and global impacts of land cover change and sea surface temperature anomalies. J. Clim. 2009, 22, 3248-3269. [CrossRef]

16. Ning, L.; Bradley, R.S. Influence of Eastern Pacific and Central Pacific El Niño events on winter climate extremes over the eastern and central United States. Int. J. Climatol. 2015, 35, 4756-4770. [CrossRef]

17. Lean, J.; Warrilow, D.A. Simulation of the regional climatic impact of amazon deforestation. Nature 1989, 342, 411-413. [CrossRef]

18. Shukla, J. Amazonian deforestation and climate change. Science 1990, 247, 1322-1324. [CrossRef] [PubMed]

19. Dirmeyer, P.A.; Shukla, J. Albedo as a modulator of climate response to tropical deforestation. J. Geophys. Res. 1994, 99, 20863-20877. [CrossRef]

20. Li, Q.P.; Ding, Y.H.; Dong, W.J. A numerical simulation on impact of historical land-use changes on regional climate in China since 1700. Acta Meteorol. Sin. 2006, 64, 257-270. (In Chinese).

21. Gao, X.J.; Zhang, D.F.; Chen, Z.X.; Pal, J.S.; Giorgi, F. Land use effects on climate in china as simulated by a regional climate model. Sci. China Earth Sci. 2007, 50, 620-628. [CrossRef]

22. Zhou, G.S.; Wang, Y.H. The feedback of land use/cover change on climate. J. Natl. Resour. 1999, 14, 318-322. (In Chinese).

23. Brovkin, V.; Ganopolski, A.; Claussen, M.; Kubatzki, C.; Petoukhov, V. Modelling climate response to historical land cover change. Glob. Ecol. Biogeogr. 1999, 8, 509-517. [CrossRef]

24. Findell, K.L.; Shevliakova, E.; Milly, P.C.D.; Stouffer, R.J. Modeled impact of anthropogenic land cover change on climate. J. Clim. 2007, 20, 3621-3634. [CrossRef]

25. Gibbard, S.G.; Caldeira, K.; Bala, G.; Phillips, T.J.; Wickett, M. Climate effects of global land cover change. Geophys. Res. Lett. 2005, 32, L23705. [CrossRef]

26. Arora, V.K.; Montenegro, A. Small temperature benefits provided by realistic afforestation efforts. Nat. Geosci. 2011, 4, 514-518. [CrossRef]

27. Zhang, F.; Li, X.; Wang, W.; Ke, X.; Shi, Q. Impacts of future grassland changes on surface climate in mongolia. Adv. Meteorol. 2013, 2013, 263746. [CrossRef]

28. Brovkin, V.; Boysen, L.; Arora, V.K.; Boisier, J.P.; Cadule, P.; Chini, L.; Claussen, M.; Friedlingstein, P.; Gayler, V.; van den Hurk, B.J.J.M.; et al. Effect of anthropogenic land-use and land-cover changes on climate and land carbon storage in CMIP5 projections for the twenty-first century. J. Clim. 2013, 26, 6859-6881.

29. Notaro, M.; Chen, G.; Liu, Z. Vegetation feedbacks to climate in the global monsoon regions. J. Clim. 2011, $24,5740-5756$.

30. Hua, W.; Chen, H. Recognition of climatic effects of land use/land cover change under global warming. Chin. Sci. Bull. 2013, 58, 3852-3858. [CrossRef]

31. Fu, Y.; Tai, A.P.K. Impacts of historical climate and land cover changes on tropospheric ozone air quality and public health in east asia over 1980-2010. Atmos. Chem. Phys. Discuss. 2015, 15, 14111-14139. [CrossRef]

32. Takata, K.; Saito, K.; Yasunari, T. Changes in the asian monsoon climate during 1700-1850 induced by preindustrial cultivation. Proc. Natl. Acad. Sci. USA 2009, 106, 9586-9589. [CrossRef] [PubMed]

33. Yan, M.; Wang, Z.; Kaplan, J.O.; Liu, J.; Min, S.; Wang, S. Comparison between reconstructions of global anthropogenic land cover change over past two millennia. Chin. Geogr. Sci. 2013, 23, 131-146. [CrossRef]

34. PAGES Science Plan and Implementation Strategy; IGBP Report No. 57; IGBP Secretariat: Stockholm, Sweden, 2009 ; p. 67.

35. Zheng, J.; Shao, X.; Hao, Z.; Ge, Q. An overview of research on climate change in China during the past 2000 years. Geogr. Res. 2010, 29, 1561-1570. (In Chinese).

36. Ge, Q.; Zheng, J.; Hao, Z.; Liu, H. General characteristics of climate changes during the past 2000 years in china. Sci. China Earth Sci. 2012, 56, 321-329. [CrossRef]

37. Ge, Q.; Hua, Z.; Zheng, J.; Fang, X.; Xiao, L.; Liu, J.; Yang, B. Forcing and impacts of warm periods in the past 2000 years. Chin. Sci. Bull. 2015, 60, 1727-1734. (In Chinese).

38. Wang, Z.Y.; Liu, J. Modeling Study on the characteristics and mechanisms of global typical warm periods over the past 2000 years. Quat. Sci. 2014, 34, 1136-1145. (In Chinese). 
39. Yan, M.; Wang, Z.Y.; Liu, J. Simulation of the characteristics and mechanisms of Chinese typical warm periods over the past 1500 years. Quat. Sci. 2014, 34, 1165-1175. (In Chinese).

40. Sun, W.; Liu, J.; Wang, Z. Modeling study on the characteristics and causes of East Asian summer monsoon precipitation on centennial time scale over the past 2000 years. Adv. Earth Sci. 2015, 30, 12-22. (In Chinese).

41. Ning, L.; Bradley, R.S. Winter climate extremes over the northeastern United States and southeastern Canada and teleconnections with large-scale modes of climate variability. J. Clim. 2015, 28, 2475-2493. [CrossRef]

42. Ning, L.; Riddle, E.; Bradley, R.S. Projected changes in climate extremes over the northeastern United States. J. Clim. 2015, 28, 3289-3310. [CrossRef]

43. Hurrell, J.W.; Holland, M.M.; Gent, P.R.; Ghan, S.; Kay, J.E.; Kushner, P.J.; Lamarque, J.F.; Large, W.G.; Lawrence, D.; Lindsay, K.; et al. The community earth system model: A framework for collaborative research. Bull. Am. Meteorol. Soc. 2013, 94, 1339-1360.

44. Lawrence, D.M.; Oleson, K.W.; Flanner, M.G.; Fletcher, C.G.; Lawrence, P.J.; Levis, S.; Swenson, S.C.; Bonan, G.B. The CCSM4 land simulation, 1850-2005: Assessment of surface climate and new capabilities. J. Clim. 2012, 25, 2240-2260. [CrossRef]

45. Lawrence, P.J.; Feddema, J.J.; Bonan, G.B.; Meehl, G.A.; O’Neill, B.C.; Oleson, K.W.; Levis, S.; Lawrence, D.M.; Kluzek, E.; Lindsay, K.; et al. Simulating the biogeochemical and biogeophysical impacts of transient land cover change and wood harvest in the community climate system model (CCSM4) from 1850 to 2100. J. Clim. 2012, 25, 3071-3095. [CrossRef]

46. Wang, Z.; Li, Y.; Liu, B.; Liu, J. Global climate internal variability in a 2000-year control simulation with community earth system model (CESM). Chin. Geogr. Sci. 2015, 25, 263-273. [CrossRef]

47. Kaplan, J.O.; Krumhardt, K.M.; Ellis, E.C.; Ruddiman, W.F.; Lemmen, C.; Goldewijk, K.K. Holocene carbon emissions as a result of anthropogenic land cover change. Holocene 2010, 21, 775-791. [CrossRef]

48. Oleson, K.W.; Larrence, D.M.; Bonan, G.B.; Flanner, M.G.; Kluzek, E.; Lawrence, P.J.; Levis, S.; Swenson, S.C.; Thornton, P.E. Technical Description of Version 4.0 of the Community Land Model (CLM); National Center for Atmospheric Research: Boulder, CO, USA, 2010.

49. Swann, A.L.; Fung, I.Y.; Chiang, J.C. Mid-latitude afforestation shifts general circulation and tropical precipitation. Proc. Natl. Acad. Sci. USA 2012, 109, 712-716. [CrossRef] [PubMed]

50. Pielke, R.A.; Pitman, A.; Niyogi, D.; Mahmood, R.; McAlpine, C.; Hossain, F.; Goldewijk, K.K.; Nair, U.; Betts, R.; Fall, S.; et al. Land use/land cover changes and climate: Modeling analysis and observational evidence. Wiley Interdiscip. Rev. Clim. Chang. 2011, 2, 828-850. [CrossRef]

51. Ning, L.; Bradley, R.S. Snow occurrence changes over the central and eastern United States under future warming scenarios. Sci. Rep. 2015, 5, 17073. [CrossRef] [PubMed]

52. Mao, R.; Gong, D.Y.; Fang, Q.M. Possible impacts of vegetation cover on local meteorological factors in growing season. Clim. Environ. Res. 2008, 13, 738-750. (In Chinese).

53. Yang, S.; Lau, K.M.; Kim, K.M. Variations of the east asian jet stream and asian-pacific-american winter climate anomalies. J. Clim. 2002, 15, 306-325. [CrossRef]

(C) 2017 by the authors. Licensee MDPI, Basel, Switzerland. This article is an open access article distributed under the terms and conditions of the Creative Commons Attribution (CC BY) license (http://creativecommons.org/licenses/by/4.0/). 